RELATIONSHIPS BETWEEN LANDSCAPE HABITAT

VARIABLES AND CHINOOK SALMON PRODUCTION

IN THE COLUMBIA RIVER BASIN

Annual Report 1999

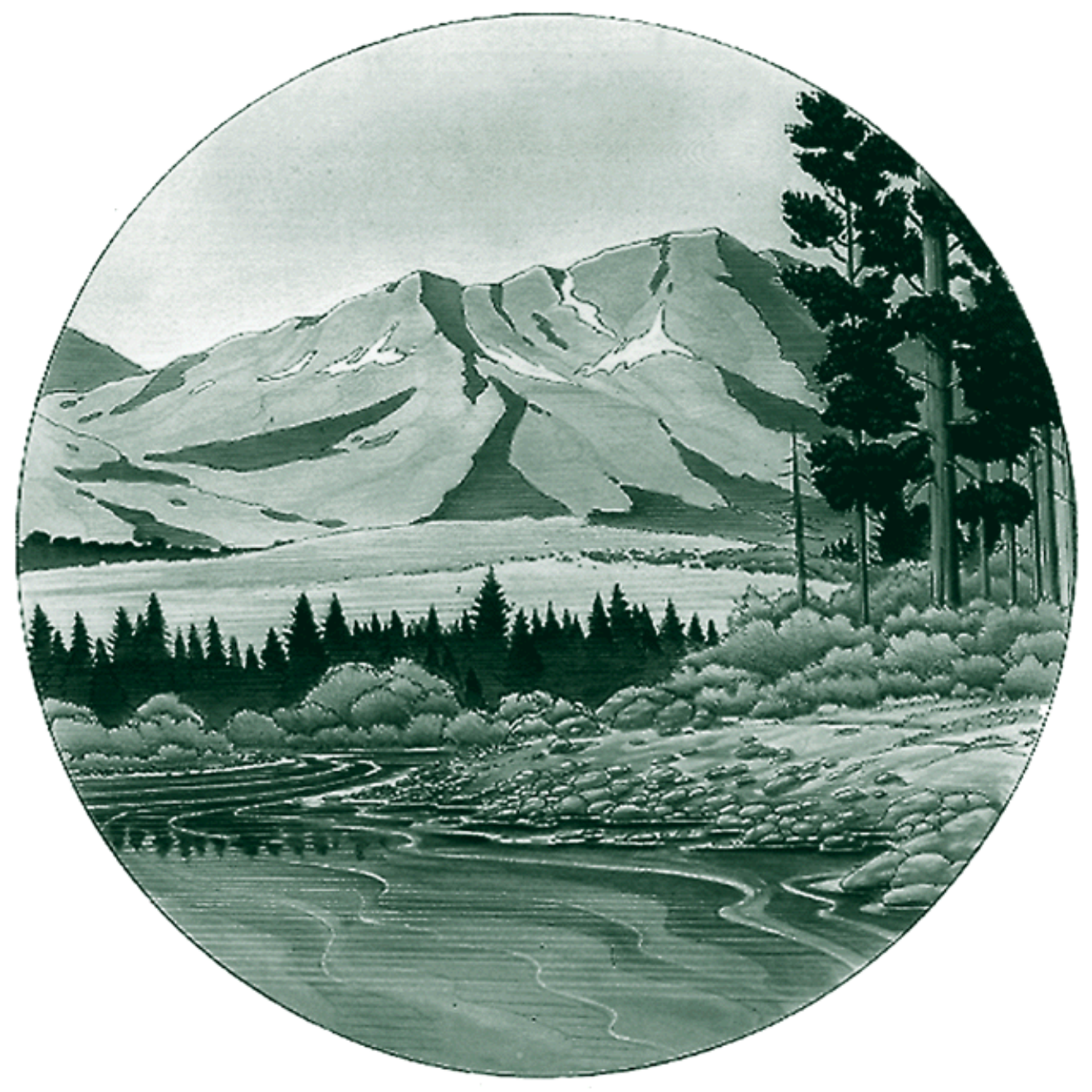

DOE/BP-25866-4 
This report was funded by the Bonneville Power Administration (BPA), U.S. Department of Energy, as part of BPA's program to protect, mitigate, and enhance fish and wildlife affected by the development and operation of hydroelectric facilities on the Columbia River and its tributaries. The views of this report are the author's and do not necessarily represent the views of BPA.

This document should be cited as follows:

Thompson, William L., D. C. Lee, U.S. Dept. of Agriculture Forest Service, 1999, Relationships Between Landscape Habitat Variables and Chinook Salmon Production in the Columbia River Basin, Annual Report 1999 to Bonneville

Power Administration, Portland, OR, Contract No. 92AI25866, Project No. 92-032-00, 23 electronic pages (BPA Report DOE/BP-25866-4)

This report and other BPA Fish and Wildlife Publications are available on the Internet at:

\section{http://www.efw.bpa.gov/cgi-bin/efw/FW/publications.cgi}

For other information on electronic documents or other printed media, contact or write to:

Bonneville Power Administration Environment, Fish and Wildlife Division

P.O. Box 3621

905 N.E. 11th Avenue

Portland, OR 97208-3621

Please include title, author, and DOE/BP number in the request. 


\title{
Relationships Between Landscape Habitat Variables and Chinook Salmon Production in the Columbia River Basin
}

\author{
Prepared by: \\ William L. Thompson \\ and \\ Danny C. Lee ${ }^{1}$
}

U.S. Department of Agriculture Forest Service, Rocky Mountain Research Station, Boise, Idaho

\author{
Prepared for: \\ U.S. Department of Energy \\ Bonneville Power Administration \\ Environment, Fish and Wildlife \\ P.O. Box 3621 \\ Portland, OR 97208-3621 \\ Project Number 92-032-00 \\ Contract Number 92AI25866
}

September 1999

${ }^{1}$ Current address: U.S.D.A. Forest Service, Sierra Nevada Conservation Framework, 801 I Street, Sacramento, CA 95814. 


\section{Introduction}

Many anadromous salmonid populations in the Pacific Northwest have dramatically declined from previously recorded levels, presumably because of degradation or loss of freshwater spawning and rearing habitats, restricted upstream access and increased downstream passage mortality due to hydroelectric dams, commercial overfishing, and negative impacts from non-native and hatchery fishes (Nehlsen et al. 1991, National Research Council 1996, Lee et al. 1997). Therefore, long-term persistence for a number of these stocks is doubtful under present conditions (e.g., see Emlen 1995, Ratner et al. 1997). Although the need for remedial measures is clear, it is unclear which factors to focus these measures on. That is, complexity of the life history pattern of these anadromous fishes, as well as variability in this pattern among different stocks (Nehlsen et al. 1991), adds to the uncertainty associated with attempting to identify limiting factors that most influence stock size and persistence. For instance, there are a wide range of potential environmental conditions that anadromous fishes experience during their freshwater occupancy period; attempting to tease out the more influential of these factors is complex and difficult (Bisson et al. 1992). In addition, efforts to properly restore anadromous salmonid stocks to previously high levels will require a broadscale approach that incorporates landscape patterns and processes (Schlosser 1991), which adds further sources of uncertainty.

A huge effort has been undertaken by various federal, state, and tribal agencies to restore populations of anadromous salmonids within the Columbia River Basin in the northwestern United States - a complex area that accomodates a variety of uses and pressures on its natural resources, including those that are incompatible with the needs of anadromous salmonids (Lee and Grant 1995). In fact, exploitation of fish and degradation of their freshwater habitats within the Columbia River Basin over the past century has reduced numbers of salmon and steelhead from an estimated 10-16 million adults to 1.5-4 million adults (Northwest Power Planning Council 1986, Lee and Grant 1995). The entire basin covers approximately $670,000 \mathrm{~km}^{2}$ in portions of seven states (mainly Idaho, western Montana, most of eastern Washington and Oregon with smaller portions in Wyoming, Utah, and Nevada) in the northwestern United States, as well as the southeastern part of British Columbia, Canada (Krutilla 1967). The sheer expanse of this basin requires salmonid recovery plans to have a broadscale approach that accounts for a complex interaction of sociopolitical, socioeconomic, and ecological issues related to salmon and salmon habitat.

An effort is currently underway by an interagency group of scientists to develop a formal decision analysis for evaluating alternative hypotheses and management options for restoration of threatened and endangered spring/summer chinook salmon (Oncorhynchus tshawytscha), fall chinook salmon, and steelhead trout (Oncorhynchus mykiss) stocks in the Columbia River Basin, a process referred to as PATH (Plan for Analyzing and Testing Hypotheses) (Marmorek and Peters 1998). A key element in this process is identifying and (when possible) resolving sources of uncertainty associated with biology and life history of anadromous salmonids as related to recovery efforts; these sources of uncertainty have been categorized as hydrosystem, habitat, hatcheries, harvest, and climate (Marmorek and Peters 1998). Although an emphasis has been placed on evaluating effects of different hydrosystem options on long-term persistence of salmonids, quality and condition of freshwater habitats may affect production in salmonids (Hunt 1969, Scarnecchia and Bergersen 1987, Heggenes and Borgstrom 1991), which in turn would 
affect their long-term persistence. However, to our knowledge, relationships between large-scale habitat factors and production in anadromous salmon stocks have never been investigated, particularly at the scale of the Columbia River Basin. Indeed, previous broadscale assessments of salmonid stocks in this area have been mainly limited to compiling available status/risk information (e.g., Nehlsen et al. 1991, Frissell 1993, Huntington et al. 1996) or using GIS data to evaluate and map potential salmon freshwater habitat (Lunetta et al. 1997; western Washington State only). Conversely, Lee et al. (1997) attempted to rigorously quantify linkages between population status of fish species (based on current population data and expert judgement) and landscape habitat variables. Nevertheless, there are no published studies that have rigorously evaluated possible linkages between broadscale habitat metrics and salmonid stock production.

Here, we investigate potential relationships between various landscape habitat variables and estimates of fish production from 25 index stocks of spring/summer chinook salmon within the Columbia River Basin. Because we use recently-described techniques for model selection and inference (Buckland et al. 1997, Burnham and Anderson 1998) that are probably unfamiliar to most ecologists, we discuss our methodological approach in some detail. Note, however, that this approach may be applied more broadly to other modeling situations, and hence should be of general interest to ecologists.

\section{Methods}

We employed a two-step modeling process to evaluate relationships between landscape variables and fish production in 25 index stocks of spring/summer chinook salmon within the Columbia River Basin (Fig. 1). The first set of models were Ricker-type stock-recruitment models (Ricker 1954). Parameter estimates from these models were used to generate a response variable in the second set of models, which contained landscape habitat predictor variables. In the following, we describe our methodological approaches for each modeling step, including state-of-the-art model selection and inference techniques adapted for our needs.

\section{Developing a Set of Candidate Models}

A crucial step in the modeling process is the construction of a set of candidate models that are ecologically meaningful (Lebreton et al. 1992, Burnham and Anderson 1998). Based on results from Deriso et al. (1996), we used a stock-recruitment, regression model with stockspecific Ricker $a$ values as a base model from which we derived other candidate models (see Stock-Recruitment Models). For the landscape habitat models, we adopted the more general approach recommended by Burnham and Anderson (1998), i.e., we developed a global linear regression model containing various class, physiographic and geophysical, and anthropogenic landscape variables (Table 1) that may have had important influences on fish production. Because of the paucity of data ( $n=25$ observations) and hence the danger of over-fitting the model, we only used a small number of predictor variables to construct the global model. From this we generated a subset of models that contained various combinations of variables we deemed biologically relevant. 


\section{Model Selection}

We used the small sample adjustment of Akaike's Information Criterion (AIC; Akaike 1973) to rank models and assess their relative plausibility given the data. AIC is an extension of likelihood theory and is derived from the Kullback-Leibler distance of information theory (Kullback and Leibler 1951, Kullback 1997), which is a measure of how much information is lost when a model is used to approximate reality (Cover and Thomas 1991, Burnham and Anderson 1998). AIC is defined as

$$
\mathrm{AIC}=n \log \left(\frac{\mathrm{RSS}}{n}\right)+2 k,
$$

where $n$ is the number of observations, $\log$ is the natural logarithm, RSS is the residual sum of squares (also called error sum of squares, SSE), and $k$ is the number of estimable parameters in the model (Buckland and Anderson 1998). Equivalently, $\mathrm{AIC}=-2 \log (\mathrm{L})+2 k$, where $\mathrm{Lis}$ the likelihood function and is calculated from the maximum likelihood estimates of the model parameters (Buckland et al. 1997). When $n / k<40$, Burnham and Anderson (1998) recommended Hurvich and Tsai's (1989) small sample adjustment to AIC,

$$
\mathrm{AICc}=\mathrm{AIC}+\frac{2 k(k+1)}{n-k-1}
$$

Note that AICc converges to AIC as the number of observations increases relative to the number of estimable parameters in a model. In other words, as $n$ increases relative to $k$ in the second term in Eq. 2, the denominator increases relative to the numerator and the whole term approaches zero. For large $n / k$ ratios, the second term essentially drops out, leaving only the AIC term. Hence, AICc can be routinely used in place of AIC because its adjustment to AIC is necessary for smaller $n / k$ ratios, whereas it is essentially equivalent to AIC for larger $n / k$ ratios.

AIC and its derivatives operate on the principle of parsimony (Box and Jenkins 1970), i.e., the highest ranked models are those that best fit the data with the fewest parameters. The principle of parsimony states that there is an ideal point in the balance between increasing the number of parameters to decrease bias and decreasing the number of parameters to increase precision. This bias/precision trade-off can be seen in the AIC formula (Eq. 1), where the first term rewards a better-fitting model (i.e., leading to lower bias) and the second term penalizes an over-parameterized model (i.e., leading to higher precision). The smaller the sum of these two terms (or the smaller the AIC), the better fitting the model. However, AIC (or AICc) is a relative ranking statistic. Therefore, AIC values should be interpreted in terms of the magnitude of their differences among candidate models rather than the magnitude of any particular value. A simple method of model ranking is to order the relative differences among AIC values by subtracting the lowest value from all other values (these differences are called $\triangle \mathrm{AIC}$ values), and then reordering $\triangle \mathrm{AIC}$ values and their associated models from low (i.e., 0) to high (Burnham and Anderson 1998). One can interpret the relative plausibility of each model for a particular data set by calculating the $\triangle \mathrm{AIC}$ model weights (see below). Note that AIC values are specific to the 
data set that was used to compute them, and hence those computed from different data sets are not comparable.

We interpreted the relative plausibility of each candidate model for a specific data set by its $\triangle \mathrm{AICc}$ weight, $w_{i}$. These weights are calculated as

$$
w_{i}=\frac{e^{\left(-\Delta \mathrm{AICc}_{i} / 2\right)}}{\sum_{i=1}^{I} e^{\left(-\Delta \mathrm{AICc}_{i} / 2\right)}}
$$

where $\triangle \mathrm{AICc}_{i}$ is the $\triangle \mathrm{AICc}$ value for the $i$ th model in a set of $I$ candidate models (Buckland et al. 1997). Thus, the $w_{i}$ sum to 1 . Note that there may be more than one model that is reasonably plausible for a particular set of data, especially if the data set is small. We decided a priori to exclude predictor variables from further consideration that occurred only in models whose $\triangle \mathrm{AICc}$ weights were less than one-tenth that of the model with the largest weight (see below). We used PROC GENMOD in SAS (SAS Institute, Inc. 1996), in conjunction with SAS programming code, to produce $\triangle \mathrm{AICc}$ values and $\triangle \mathrm{AICc}$ weights for all sets of candidate models.

\section{Model Inference}

We incorporated model selection uncertainty into model inference as generally described by Buckland et al. (1997) and Burnham and Anderson (1998). That is, we did not select a single model from a candidate set and treat it as the "true" model unless the $\triangle \mathrm{AICc}$ weight was more than ten times the next highest weight (our modification). Rather, we viewed the predictor variables contained in models whose $\triangle \mathrm{AICc}$ weights were more than one-tenth of the largest $\triangle \mathrm{AICc}$ weight as forming a composite conceptual model whose parameter estimates were computed based on the $\triangle \mathrm{AICc}$-weighted average of estimates from relevant models. This arbitrary rule based on proportion of the maximum $\triangle \mathrm{AICc}$ weight was used to limit the number of predictors in our composite conceptual model to those that seemed reasonably plausible for the data.

We computed model-averaged estimates of regression coefficients for relevant predictor variables via

$$
\hat{\bar{\theta}}=\sum_{i=1}^{J} w_{i} \hat{\theta}_{i}
$$

where $\hat{\theta}_{i}$ is the estimator of a regression coefficient for a specific predictor variable in model $i$ and $w_{i}$ is the $\triangle \mathrm{AICc}$ weight that is calculated from the AICc values for the $J$ candidate models containing a specific predictor variable (Buckland et al. 1997). For example, say 3 of the 8 candidate models contained predictor $\mathrm{X}_{1}$, which appeared in at least one model with $w_{i}$ greater 
than one-tenth of the maximum $w_{i}$. The $w_{i}$ used in the model selection process for assessing the plausibility of each model would be based on $\triangle \mathrm{AICc}$ values from all 8 models, whereas the $w_{i}$ used in model inference for estimating the overall regression coefficient (i.e., $\hat{\bar{\theta}}$ ) for $\mathrm{X}_{1}$ would only be based on $\triangle \mathrm{AICc}$ values calculated from the $J=3$ models containing $\mathrm{X}_{1}$. Thus, the $w_{i}$ always were scaled so that they summed to 1 .

Variance estimators for regression coefficients also were calculated based on model averaging. There were two sources of uncertainty associated with each model parameter estimate: the variance based on a particular model (called conditional variance) and the variance due to uncertainty in the selection from a set of models (Buckland et al. 1997). The overall variance (called unconditional variance, vâr $(\hat{\theta})$ ) is calculated as

$$
\operatorname{varr}(\hat{\theta})=\left[\sum_{i=1}^{J} w_{i} \sqrt{\operatorname{var}\left(\hat{\theta_{i}} \mid \theta\right)+\left(\hat{\theta}_{i}-\hat{\theta}\right)^{2}}\right]^{2},
$$

where vâr $\left(\hat{\theta}_{i} \mid \theta\right)$ is the conditional variance (i.e., the square of the standard error for regression coefficients in regression output) and $\left(\hat{\theta}_{i}-\hat{\bar{\theta}}\right)^{2}$ is the variance component due to model selection uncertainty. The $w_{i}$ were computed based on the $J$ models as described above. Technically, estimators should have been perfectly correlated for Eq. 5 to be used so that there would be no covariance term (Buckland et al. 1997); however, reasonable results can be obtained for a correlation between 0.5 and 1 (K. P. Burnham, pers. commun.).

\section{Stock-Recruitment Models}

Deriso et al. (1996) conducted preliminary analyses of spawner-recruit data from 13 index stocks of spring/summer chinook salmon in part to evaluate which Ricker-type model best fit the data, and to use the selected model to generate Ricker $a$ estimates for further analyses (see below). Based on an AIC selection criterion, the best approximating model chosen was the one with no spawner measurement error and stock-specific Ricker $a$ values,

$$
\ln R_{t, i}=\ln S_{t, i}+a_{i}+\delta_{t}-b_{i} S_{t, i}-m_{t, i}+\varepsilon_{t, i}
$$

where $R_{t, i}$ is the Columbia River observed spawning returns (recruitment) for stock $i$ during year $t, S_{t, i}$ is the observed spawners for stock $i$ during year $t, a_{i}$ is the Ricker $a$ parameter for stock $i$, $b_{i}$ is the Ricker $b$ parameter for stock $i, \delta_{t}$ is the year-effect parameter for year $t, m_{t, i}$ is the inriver passage mortality for stock $i$ during year $t$, and $\varepsilon_{t, i}$ is the multiplicative residual error 
(assumed to be distributed as $\mathbf{N}\left(0, \sigma_{\varepsilon}^{2}\right)$; Deriso et al. 1996). Ricker $a$ is a measure of productivity (recruits-per-spawner) at low numbers of fish, whereas Ricker $b$ is a measure of the rate of decrease in productivity as fish numbers increase (Hilborn and Walters 1992). Hereafter we simply refer to these parameters as $a$ and $b$, subscripted by stock $i$ when appropriate. The year-effect parameter accounts for other factors affecting all stocks such as regional changes in terrestrial climate and large changes in survival rates of chinook salmon in the marine environment (i.e., this model assumes that large annual variation in ocean mortality is limited to the first 2 years of life; Deriso et al. 1996).

The in-river passage mortality is the sum of two components, $X$ and $\mu_{t}$. The first component is the number of dams encountered by chinook salmon during downstream migration, $X$, which is defined differently depending on year. During recording years 1952-1969, this component is the actual number of dams encountered between the spawning/rearing area and the lowest dam in the system (Bonneville Dam; Fig. 1) inclusive (range $=1-9$ dams), whereas during 1970-1990 it is the number of dams between John Day Dam and Bonneville Dam (i.e., 3). The second component of in-river passage mortality is the net dam passage mortality, $\mu_{t}$, from the Snake River stocks to the John Day Dam during 1970-1990 (Deriso et al. 1996). Thus, through 1969 , the in-river passage mortality is the actual number of dams encountered by chinook salmon from each stock during downstream migration (i.e., from 1 to 9 dams), whereas after 1969 it is the number of dams encountered between John Day Dam and Bonneville Dam (the number was fixed at 3) plus the net dam passage mortality from the Snake River stocks to the John Day Dam.

Deriso et al's (1996) choice of the stock-specific Ricker $a$ model in Eq. 6 was consistent with the rationale that, because of the depressed levels of many spring/summer chinook stocks, $a_{i}$ would be better than $b_{i}$ for evaluating effects of habitat on fish production. Thus, Eq. 6 was used in preliminary analyses by the PATH group to generate estimates of $a$ for each of the 25 index stocks (which included 12 additional stocks - see below), which then were to be used as the response variable in a set of linear regression models containing various combinations of class, physiographic and geophysical, and anthropogenic landscape variables (Table 1). However, spawner-recruit data from the John Day Middle Fork during 1959-1973 had an unusually large influence on parameter estimates, including $a_{i}$, generated by the model in Eq. 6 (R. Hinrichsen, pers. commun.). Therefore, we needed to remove the pre-1974 data from John Day Middle Fork and refit at least some of the Ricker-type models considered by Deriso et al. (1996) to see if Eq. 6 still would be chosen as the best approximating model. Further, Beamesderfer et al. (1997) and R. Beamesderfer (Oregon Dept. of Fish and Wildlife) provided spawner-recruit data for an additional 12 stocks, which afforded us the opportunity to more rigorously evaluate the relative importance of the Ricker-type models. Consequently, as per a general suggestion by R. Deriso (Inter-American Tropical Tuna Commission), we considered a set of 8 candidate Ricker-type models, including Eq. 6, and 7 others that differed from Eq. 6 by the Ricker $a$ term and/or the in-river passage mortality term (Table 2). 


\section{Landscape Habitat Models}

Habitat data for physiographic, geophysical, and anthropogenic landscape variables (Table 1) were obtained from the Interior Columbia Basin Ecosystem Management Project (Lee et al. 1997). These landscape variables are at the HUC6 or subwatershed level of spatial scale, which is about 7,800 ha on average within the Columbia Basin (Lee et al. 1997). Because the model containing common $a$ values was the only plausible model given the data (see Results), we used $\hat{d}_{i}=\hat{a}-\ln \left(\hat{b}_{i}\right)$ (R. Deriso, pers. commun.) instead of $\hat{a}_{i}$ as the response variable in the landscape habitat models. Note that $e^{\hat{d}_{i}-1}$ is the estimator of maximum recruitment for the $i$ th stock. To incorporate the uncertainty associated with $\hat{d}_{i}$ into the model parameter estimates, we generated 1000 random $\hat{d}_{i}$ values from a normal distribution with mean $\left(d_{i}\right)$ and $\operatorname{var}\left(d_{i}\right)$, fit each of the candidate models 1000 times, and averaged over the 1000 parameter estimates and AICc values to obtain single values for each candidate model. Given mean $\left(d_{i}\right)=\operatorname{mean}(a)-$ mean $\left(\ln \left[b_{i}\right]\right)$, we obtained an estimate of mean $(a)$ from the regression output. The method of moments (Wackerly et al. 1996) was used to define mean $\left(\ln \left[b_{i}\right]\right)$, which was lognormally distributed with mean $e^{\mu_{i}+\frac{1}{2} \sigma_{i}^{2}}$, in terms of the sample mean $\left(m_{i}\right)$ and variance $\left(s_{i}^{2}\right)$ of $b_{i}$. Thus,

$$
\operatorname{mean}\left(\ln \left[b_{i}\right]\right)=2 \ln \left(m_{i}\right)-\frac{1}{2} \ln \left(s_{i}^{2}+m_{i}^{2}\right)
$$

where $m_{i}$ and $s_{i}^{2}$ were obtained from regression output. The general formula for the variance of $d_{i}$ is

$$
\operatorname{var}\left(d_{i}\right)=\operatorname{var}(a)+\operatorname{var}\left(\ln \left[b_{i}\right]\right)-\operatorname{cov}\left(a, \ln \left[b_{i}\right]\right) .
$$

Because estimates of the second and third terms were not available, we used the delta method (Rao 1965, Oehlert 1992, White 1998) to define the variance of $d_{i}$ in terms of the variance and covariance estimators of $a$ and $b_{i}$. In general, the variance for the function of 2 random variables, such as $d_{i}=a-\ln \left(b_{i}\right)$, may be derived via

$$
\operatorname{var}\left(d_{i}\right)=\left(\frac{\partial d_{i}}{\partial \theta_{j}}\right) \bullet \sum \bullet\left(\frac{\partial d_{i}}{\partial \theta_{j}}\right)^{\prime}
$$


where $\theta_{j}$ is the $j$ th random variable, $\left(\frac{\partial d}{\partial \theta_{j}}\right)$ is the row vector of partial derivatives with respect to $\theta_{j},\left(\frac{\partial d}{\partial \theta_{j}}\right)^{\prime}$ is the column vector of partial derivatives with respect to $\theta_{j}$, and $\sum$ is the variance-covariance matrix of the $\theta_{j}$ (White 1998). In this case, $\theta_{1}=a$ and $\theta_{2}=b_{i}$. Thus, the variance of $d_{i}$ is derived using

$$
\operatorname{var}\left(d_{i}\right)=\left[\begin{array}{ll}
\frac{\partial d_{i}}{\partial a} & \frac{\partial d_{i}}{\partial b_{i}}
\end{array}\right] \bullet\left[\begin{array}{cc}
\operatorname{var}(a) & \operatorname{cov}\left(a, b_{i}\right) \\
\operatorname{cov}\left(a, b_{i}\right) & \operatorname{var}\left(b_{i}\right)
\end{array}\right] \bullet\left[\begin{array}{c}
\frac{\partial d_{i}}{\partial a} \\
\frac{\partial d_{i}}{\partial b_{i}}
\end{array}\right]
$$

which reduces to

$$
\operatorname{var}\left(d_{i}\right)=\left(\frac{\partial d_{i}}{\partial a}\right)^{2} \operatorname{var}(a)+\left(\frac{\partial d_{i}}{\partial b_{i}}\right)^{2} \operatorname{var}\left(b_{i}\right)+2\left(\frac{\partial d_{i}}{\partial a}\right)\left(\frac{\partial d_{i}}{\partial b_{i}}\right) \operatorname{cov}\left(a, b_{i}\right)
$$

Given $\frac{\partial d_{i}}{\partial a}=1$ and $\frac{\partial d_{i}}{\partial b_{i}}=-\frac{1}{b_{i}}$, the variance of $d_{i}$ is defined as

$$
\operatorname{var}\left(d_{i}\right)=\operatorname{var}(a)+\frac{1}{b_{i}^{2}} \operatorname{var}\left(b_{i}\right)-\frac{2}{b_{i}} \operatorname{cov}\left(a, b_{i}\right)
$$

where estimates for $b_{i}, \operatorname{var}(a), \operatorname{var}\left(b_{i}\right)$, and $\operatorname{cov}\left(a, b_{i}\right)$ are obtained from regression output.

After deriving estimators for $d_{i}$ needed to parameterize its distribution for generating 1000 random values, we constructed a global linear regression model containing various physiographic, geophysical, and anthropogenic landscape variables (Table 1) that may have had important influences on maximum recruitment. Habitat data were standardized based on mean 0 and standard deviation 1 so that magnitude of regression coefficients could be interpretable across predictor variables. We also included a class variable, REGION (Table 1, Fig. 1), as a predictor based on preliminary modeling results where $\hat{a}_{i}$ was the response variable.

Residual and normal probability plots were generated for the global model to check for any serious departures from the model assumptions for linear regression. If no serious departures were detected, we fit the set of class and habitat variables in regression models with $\hat{d}_{i}$ as the response variable. SAS (SAS Institute, Inc. 1996) was used to generate 1000 $\hat{d}_{i}$ values, fit these to each habitat model, and generate $\triangle \mathrm{AICc}$ values, $\triangle \mathrm{AICc}$ weights, estimated regression coefficients, and estimated standard errors. 
We assessed statistical significance of predictor variables by whether the confidence intervals for their estimated regression coefficients contained 0 , and biological importance by whether these intervals contained a range of values of a magnitude that could be considered ecologically meaningful (Yoccoz 1991, Gerard et al 1998). Because choice of confidence level is arbitrary, we computed $90 \%, 95 \%$, and $99 \%$ confidence intervals (based on a t-statistic with $n-1$ degrees of freedom) to display a range of confidence levels.

\section{Results}

The stock-recruitment model containing a common Ricker $a$ was the only plausible model in our set of candidate models for our data. This was true regardless of inclusion or exclusion of pre-1974 spawner-recruitment data from John Day Middle Fork (Table 3).

Therefore, we treated $a$ and $b_{i}$ estimates from this model as "true" estimates (i.e., no modelaveraging was necessary). Interestingly, the model containing $a_{i}$ (Eq. 6) was highly implausible in both cases.

Ricker $a$ estimates were similar between common Ricker $a$ models both with $(\hat{a}[\hat{\mathrm{SE}}]=1.74[0.39])$ and without $(\hat{a}[\hat{\mathrm{S} E}]=1.85[0.39])$ pre-1974 John Day Middle Fork data. Further, an $x-y$ plot of $b_{i}$ from both models closely followed a straight-line relationship, which indicated estimates were similar in size and ordering. Thus, we used estimates from the common Ricker $a$ model with pre-1974 John Day Middle Fork data for generating the response variable $\left(\hat{d}_{i}\right)$ for the habitat models (Table 4$)$.

Residual and normal probability plots generated from the global landscape habitat model did not reveal any serious violations of assumptions underlying the linear regression model; hence, we assumed a linear regression model was appropriate for all subsets of the global model. The landscape model containing mean elevation, percent managed forests, and percent USFS low impact and wilderness areas, was the most plausible $(\triangle \mathrm{AICc}=0.37)$ model, given the data, in the set of models (Table 5). However, 5 other models had $\triangle \mathrm{AICc}$ values that were at least one-tenth of $\triangle \mathrm{AICc}=0.37$, including those containing mean annual precipitation, mean annual temperature, and geometric mean road density. Model-averaged parameter estimates for these 6 predictor variables showed statistically significant negative relationships between estimated maximum recruitment of spring/summer chinook salmon and both percent managed forest $(95 \%$ level) and mean elevation (90\% level) (Table 6). However, we felt only the $90 \%$ confidence interval associated with percent managed forests contained a range of values with magnitudes of biological importance. Thus, as percent managed forest increased, maximum recruitment (i.e., carrying capacity) of salmon decreased.

\section{Discussion}

There are a several obvious shortcomings in our analyses. First, stocks used in our analyses were not a random sample from all possible stocks within the Interior Columbia River Basin, but rather included those stocks that had adequate numbers of fish and data to generate spanwer-recruit data. Thus, inferences beyond our index streams are problematic. However, 
analysis of boxplots generated by physiographic and geophysical variables from index areas revealed that they were mostly within the range of values for the lower Columbia, midColumbia, Snake regions (Fig. 1) as a whole. Therefore, based on landscape habitat variables, we assumed that index streams were representative of chinook spawning/rearing streams in the entire Interior Columbia River Basin.

Second, inferences based on landscape variables are obviously scale dependent. That is, inferences are limited to the scale of our predictor variables; localized physiographic, geophysical and anthropogenic variables that may be affecting maximum recruitment of chinook salmon may not be discernible at the landscape scale. Thus, a negative relationship between percent managed forests and maximum recruitment of chinook salmon should be interpreted relative to index stocks at the subwatershed level and across the Interior Columbia River Basin rather than applying it on a finer scale, such as attempting to draw conclusions based on percent managed forests along a particular stream reach.

Third, our estimates of maximum recruitment were not scaled by size of area containing a particular stock because there was not a strong correlation (Pearson correlation coefficient $=$ 0.30 ) between maximum recruitment and length of perennial streams for each stock area. Unfortunately, we did not have estimates of the amount or percentage of spawning/rearing habitat (or quality therein) within areas containing each stock, and therefore we assumed that length of perennial streams was an adequate surrogate for this metric. Note that variables based on percent composition, like percentage managed forests, would be unaffected by scaling.

Despite their shortcomings, our analyses produced some interesting results. Given the level of uncertainty and noise inherent in our data, detecting any signal at all is in itself noteworthy. This lends support to the idea that, despite the uncertainty involved, broadscale analyses can be worthwhile. Beyond this, one of the more interesting of our results was that the stock-recruitment model containing a common Ricker $a$ was the only plausible model for our data. This is surprising because of the apparent soundness of the biological rationale for using stock-specific Ricker $a$ values, being a measure of fish production at low stock sizes, to help discern differences in spawning/rearing habitats across stocks of chinook salmon that are at historically low levels. However, previous analyses in which $a$ values were used in the response variable in landscape habitat models indicated REGION (Table 1; Fig. 1) was the only variable that was statistically significant. This result implies that any differences in $a$ values among stocks were overwhelmed by the uncertainty in the region effect. Conversely, REGION was not even contained in a plausible habitat model when maximum recruitment was the response variable. This contrast in results reinforces the importance of model selection to the overall modeling process. Given the implausibility of the stock-specific Ricker $a$ model for these spawner-recruit data, we recommend maximum recruitment be used instead of $a$ values in any PATH retrospective or prospective analysis of potential effects of broadscale habitat changes on productivity of spring/summer chinook in the 25 index stocks.

The negative relationship between maximum recruitment and percentage of forests with moderate to high intensity management status warrants consideration of forest management practices as a factor to be included in the PATH prospective analyses. However, a more rigorous, experimental management approach (Walters 1986, Walters 1997) is needed to better 
understand broadscale effects of land management actions on spawning/rearing habitat of spring/summer chinook stocks. There is too much uncertainty associated with the life history patterns of anadramous salmon for us to expect a clear answer from correlative data, which is why an experimental management approach has been incorporated into the objectives of PATH (Marmorek and Peters 1998). Although this paper does not resolve uncertainties related to broadscale habitat features and production of spring/summer chinook, it does provide direction for future research that we hope will ultimately answer fundamental questions related to conservation of anadromous salmon in the Columbia River Basin.

\section{Acknowledgments}

We thank C. Paulsen, M. Jones, and R. King for reviewing earlier drafts of this manuscript. We especially thank R. Beamesderfer, H. Schaller, M. Zimmerman, C. Petrosky, O. Langness, and L. LaVoy for providing spawner-recruit data for our analyses. C. Paulsen graciously provided SAS code for fitting Eq. 6. We also thank R. Deriso for his help with the stock-recruitment models. This work was funded by Bonneville Power Administration under project 92-32.

\section{References}

Akaike, H. 1973. Information theory and an extension of the maximum likelihood principle. Pages 267-281 in B. N. Petrov and F. Csaki, editors. Second International Symposium on Information Theory. Akademiai Kiado, Budapest, Hungary.

Beamesderfer, R. C. P., H. A. Schaller, M. P. Zimmerman, C. E. Petrosky, O. P. Langness, and L. LaVoy. 1998. Spawner-recruit data for spring and summer chinook salmon populations in Idaho, Oregon, and Washington. Pages 1-78 in D. R. Marmorek and C. N. Peters, editors. Plan for analyzing and testing hypotheses (PATH): retrospective and prospective analyses of spring/summer chinook reviewed in FY 1997. Compiled and edited by ESSA Technologies, Limited, Vancouver, British Columbia, Canada. Available: http://www.efw.bpa.gov/Environment/PATH/reports/1997retro/toc.htm

Bisson, P. A., T. P. Quinn, G. H. Reeves, and S. V. Gregory. 1992. Best management practices, cumulative effects, and long-term trends in fish abundance in Pacific Northwest river systems. Pages 189-232 in R. J. Naiman, editor. Watershed management: balancing sustainability. Springer-Verlag, New York, New York, USA.

Box, G. E. P., and G. M. Jenkins. 1970. Time series forecasting: Forecasting and control. Holden-Day, London, U.K.

Buckland, S. T., K. P. Burnham, and N. H. Augustine. 1997. Model selection: an integral part of inference. Biometrics 53:603-618.

Burnham, K. P., and D. R. Anderson. 1998. Model selection and inference: a practical information theoretic approach. Springer-Verlag, New York, New York, USA. 
Cover, T. M., and J. A. Thomas. 1991. Elements of information theory. John Wiley, New York, New York, USA.

Daly, C., R. P. Neilson, and D. L. Phillips. 1994. A statistical-topographic model for mapping climatological precipitation over mountainous terrain. Journal of Applied Meteorology 33:140-158.

Deriso, R., D. R. Marmorek, and I. Parnell. 1996. Retrospective analysis of passage mortality of spring chinook of the Columbia River. Pages 5-1 to 5-29 in D. R. Marmorek and C. N. Peters, eds. Plan for analyzing and testing hypotheses (PATH): final report on retrospective analyses for fiscal year 1996. Compiled and edited by ESSA Technologies, Limited., Vancouver, British Columbia, Canada. Information for obtaining copies is available at: http://www.efw.bpa.gov/Environment/PATH/

Emlen, J. M. 1995. Population viability of the Snake River chinook salmon (Oncorhynchus tshawytscha). Canadian Journal of Fisheries and Aquatic Sciences 52:1442-1448.

Frissell, C. A. 1993. Topology of extinction and endangerment of native fishes in the Pacific Northwest and California (U.S.A.). Conservation Biology 7:342-354.

Gerard, P. D., D. R. Smith, and G. Weerakkody. 1998. Limits of retrospective power analysis. Journal of Wildlife Management 62:801-807.

Heggenes, J., and R. Borgstrom. 1991. Effect of habitat types on survival, spatial distribution, and production of an allopatric cohort of Atlantic salmon, Salmo salar L., under conditions of low competition. Journal of Fish Biology 38:267-280.

Hilborn, R., and C. J. Walters. 1992. Quantitative fisheries stock assessment: choice, dynamics and uncertainty. Chapman and Hall, New York, New York, USA.

Hunt, R. L. 1969. Effects of habitat alteration on the production, standing crops, and yield of brook trout in Lawerence Creek, Wisconsin. Pages 281-312 in T.G. Northcote, editor. H.R. MacMillan Lectures in Fisheries. Vancouver University, Vancouver, British Columbia, Canada.

Huntington, C., W. Nehlsen, and J. Bowers. 1996. A survey of healthy native stocks of anadromous salmonids in the Pacific Northwest and California. Fisheries 21(3):6-14.

Hurvich, C. M., and C. Tsai. 1989. Regression and time series model selection in small samples. Biometrika 76:297-307.

Krutilla, J. V. 1967. The Columbia River Treaty: the economics of an international river basin development. Johns Hopkins, Baltimore, Maryland, USA.

Kullback, S. 1997. Information theory and statistics (reprinted). Dover Publications, New York, New York, USA. 
Kullback, S., and R. A. Leibler. 1951. On information and sufficiency. Annals of Mathematical Statistics 22:79-86.

Lebreton, J.-D., K. P. Burnham, J. Clobert, and D. R. Anderson. 1992. Modeling survival and testing biological hypotheses using marked animals: a unified approach with case studies. Ecological Monographs 62:67-118.

Lee, D. C., and W. E. Grant. 1995. A hierarchical approach to fisheries planning and modeling in the Columbia River Basin. Environmental Management 19:17-25.

Lee, D. C., J. R. Sedell, B. E. Rieman, R. F. Thurow, J. E. Williams, D. Burns, J. Clayton, L. Decker, R. Gresswell, R. House, P. Howell, K. M. Lee, K. Macdonald, J. McIntyre, S. McKinney, T. Noel, J. E. O'Connor, C. K. Overton, D. Perkinson, K. Tu, and P. Van Eimeren. 1997. Broadscale assessment of aquatic species and habitats. Pages 1057-1713 in T. M. Quigley and S. J. Arbelbide, technical editors. An assessment of ecosystem components in the Interior Columbia Basin and portions of the Klamath and Great Basins. Volume III. U.S.D.A. Forest Service, General Technical Report PNW-GTR405, Portland, Oregon, USA.

Lunetta, R. S., B. L. Cosentino, D. R. Montgomery, E. M. Beamer, and T. J. Beechie. 1997. GIS-based evaluation of salmon habitat in the Pacific Northwest. Photogrammetric Engineering \& Remote Sensing 63:1219-1229.

Marmorek, D. R., and C. N. Peters, editors. 1998. Plan for analyzing and testing hypotheses (PATH): retrospective and prospective analyses of spring/summer chinook reviewed in FY 1997. Compiled and edited by ESSA Technologies, Limited, Vancouver, British Columbia, Canada. Available: http://www.efw.bpa.gov/Environment/PATH/

National Research Council. 1996. Upstream: salmon and society in the Pacific Northwest. National Research Council, Washington, D.C., USA. Chapter 3:39-66.

Nehlsen, W., J. E. Williams, and J. A. Lichatowich. 1991. Pacific salmon at the crossroads: stocks at risk from California, Oregon, Washington, and Idaho. Fisheries 16(2):4-21.

Northwest Power Planning Council. 1986. Compilation of information on salmon and steelhead losses in the Columbia River Basin. Northwest Power Planning Council, Portland, Oregon, USA.

Oehlert, G. W. 1992. A note on the delta method. American Statistician 46:27-29.

Rao, C. R. 1965. Linear statistical inference and its applications. John Wiley, New York, New York, USA.

Ratner, S., R. Lande, and B. B. Roper. 1997. Population viability analysis of spring chinook salmon in the South Umpqua River, Oregon. Conservation Biology 11:879-889. 
Ricker, W. E. 1954. Stock and recruitment. Journal of the Fisheries Research Board of Canada 11:559-623.

SAS Institute, Incorporated. 1996. SAS/STAT software: changes and enhancements, through version 6.11. SAS Institute, Incorporated, Cary, North Carolina, USA.

Scarnecchia, D. L., and E. P. Bergersen. 1987. Trout production and standing crop in Colorado's small streams, as related to environmental features. North American Journal of Fisheries Management 7:315-330.

Schlosser, I. J. 1991. Stream fish ecology: a landscape perspective. Bioscience 41:704-712.

Wackerly, D. D., W. Mendenhall, III, and R. L. Scheaffer. 1996. Mathematical statistics with applications. Fifth edition. Duxbury Press, Belmont, California, USA.

Walters, C. 1997. Challenges in adaptive management of riparian and coastal ecosystems. Conservation Ecology [online] 1(2):1-24. Available: http://www.consecol.org/vol1/iss2/art1

Walters, C. J. 1986. Adaptive management of renewable resources. McMillan, New York, New York, USA.

White, G. C. 1998. The delta method. Available: http://neota.cnr.colostate.edu/fw663/Mark.html (20 March 1998).

Williams, J. E., J. E. Johnson, D. A. Hendrickson, S. Contreras-Balderas, J. D. Williams, M. Navarro-Mendoza, D. E. McAllister, and J. E. Deacon. 1989. Fishes of North America endangered, threatened, or of special concern. Fisheries 14(6):2-20.

Yoccoz, N. G. 1991. Use, overuse, and misuse of significance tests in evolutionary biology and ecology. Bulletin of the Ecological Society of America 72:106-111. 
Table 1. Category, name, and description of landscape variables included in a set of linear regression models attempting to predict fish production for 25 index stocks of spring/summer chinook salmon within the Columbia River Basin. Physiographic, geophysical, and anthropogenic variables are at the HUC6 code (subwatershed) level (Lee et al. 1997). The term weighted indicates that the variable was weighted by spatial areas of the subwatersheds where a particular stock occurred, i.e., if the stream section stretched over more than one subwatershed.

\begin{tabular}{llll}
\hline Category & Variable Name & Description & \\
\hline Class & REGION ${ }^{1}$ & Name & Fourth Hydrologic Field (HUC4) \\
& & Lower Columbia (LC) & $\begin{array}{c}17070101-17070106, \\
17070201-17070204, \\
17070301-17070307\end{array}$ \\
& & Mid-Columbia (MC) & $17020001-17020016$ \\
& & Snake (SN) & $17060101-17060107,17060110$, \\
& & & $17060201-17060210$
\end{tabular}

1 See Fig. 1 for a graphical display of the three regions. 
Table 2. Formula, number and name, and description of Ricker-type models composing the candidate set that were fitted with spawner-recruit data from 25 index stocks of spring/summer chinook salmon in the Columbia River Basin. Water transit time (WTT) is the number of days, on average, required for water to pass from the head of lower Granite Dam reservoir to Bonneville Dam during salmon spring migration (Deriso et al. 1996; Fig. 1). REGION is described in Table 1; all other terms in the equations are defined in the text.

\begin{tabular}{|c|c|c|}
\hline Model Formula & Model Number and Name & Description \\
\hline $\ln R_{t, i}=\ln S_{t, i}+a_{i}+\delta_{t}-b_{i} S_{t, i}-X-\mu_{t}+\varepsilon_{t, i}$ & (1) Stock-specific Ricker $a$ & $\begin{array}{l}\text { Same as Eq. } 6 \text {; in-river } \\
\text { passage mortality is the } \\
\text { actual number of dams } \\
\text { encountered }(X) \text { plus } \mu_{t} \text {. } \\
\text { Same as Model }(1) \text { except } \\
\text { Ricker } a \text { is assumed to be } \\
\text { the same across all stocks, } \\
\text { and is contained in the } \\
\text { intercept term, } \beta_{0} .\end{array}$ \\
\hline $\ln R_{t, i}=\ln S_{t, i}+a_{i}+\delta_{t}-b_{i} S_{t, i}-X-\mu_{t}^{*}+\varepsilon_{t, i}$ & $\begin{array}{l}\text { (3) Stock-specific Ricker } a \text {, } \\
\text { common } \mu_{t}\end{array}$ & $\begin{array}{l}\text { Same as Model (1) except } \\
\text { the net dam passage } \\
\text { mortality is assumed to be } \\
\text { the same across all regions, } \\
\mu_{t}^{*} \text {. }\end{array}$ \\
\hline $\ln R_{t, i}=\beta_{0}+\ln S_{t, i}+\delta_{t}-b_{i} S_{t, i}-m_{t, i}+\varepsilon_{t, i}$ & $\begin{array}{l}\text { (4) Common Ricker } a \text {, } \\
\text { common } \mu_{t}\end{array}$ & $\begin{array}{l}\text { Same as Model (3) except } \\
\text { Ricker } a \text { is assumed to be } \\
\text { the same across stocks, and } \\
\text { is contained in the intercept } \\
\text { term, } \beta_{0} \text {. }\end{array}$ \\
\hline $\begin{array}{c}\ln R_{t, i}=\ln S_{t, i}+a_{i}+\delta_{t}-b_{i} S_{t, i}- \\
R E G I O N{ }^{*} W T T+\varepsilon_{t, i}\end{array}$ & $\begin{array}{l}\text { (5) Stock-specific Ricker } a \text {, } \\
\text { REGION*WTT }\end{array}$ & $\begin{array}{l}\text { Same as Model (1) except } \\
\text { the in-river passage } \\
\text { mortality is set equal to the } \\
\text { interaction between region } \\
\text { and water transit time. }\end{array}$ \\
\hline $\begin{array}{c}\ln R_{t, i}=\beta_{0}+\ln S_{t, i}+\delta_{t}-b_{i} S_{t, i}- \\
R E G I O N * W T T+\varepsilon_{t, i}\end{array}$ & $\begin{array}{l}\text { (6) Common Ricker } a \text {, } \\
\text { REGION*WTT }\end{array}$ & $\begin{array}{l}\text { Same as Model (5) except } \\
\text { Ricker } a \text { is assumed to be } \\
\text { the same across stocks, and } \\
\text { is contained in the intercept } \\
\text { term, } \beta_{0} \text {. }\end{array}$ \\
\hline $\ln R_{t, i}=\ln S_{t, i}+a_{i}+\delta_{t}-b_{i} S_{t, i}-W T T+\varepsilon_{t, i}$ & $\begin{array}{l}\text { (7) Stock-specific Ricker } a \text {, } \\
\text { common WTT }\end{array}$ & $\begin{array}{l}\text { Same as Model (1) except } \\
\text { the in-river passage } \\
\text { mortality is set equal to the } \\
\text { water transit time. }\end{array}$ \\
\hline $\ln R_{t, i}=\beta_{0}+\ln S_{t, i}+\delta_{t}-b_{i} S_{t, i}-W T T+\varepsilon_{t, i}$ & $\begin{array}{l}\text { (8) Common Ricker } a \text {, } \\
\text { common WTT }\end{array}$ & $\begin{array}{l}\text { Same as Model (7) except } \\
\text { Ricker } a \text { is assumed to be } \\
\text { the same across stocks, and } \\
\text { is contained in the intercept } \\
\text { term, } \beta_{0} \text {. }\end{array}$ \\
\hline
\end{tabular}


Table 3. Model description, AICc values, $\triangle \mathrm{AICc}$ values, and $\triangle \mathrm{AICc}$ weights for two sets of Ricker-type models generated with and without spawner-recruitment data of spring/summer chinook salmon from pre-1974 John Day Middle Fork. $\triangle \mathrm{AICc}$ weights represent relative degree of plausiblity for each model given the data.

\begin{tabular}{|c|c|c|c|c|c|c|}
\hline \multirow[b]{2}{*}{ Model } & \multicolumn{3}{|c|}{$\begin{array}{c}\text { With pre-1974 John Day } \\
\text { Middle Fork Data }\end{array}$} & \multicolumn{3}{|c|}{$\begin{array}{c}\text { Without pre-1974 John Day } \\
\text { Middle Fork Data }\end{array}$} \\
\hline & $\mathrm{AICc}$ & $\triangle \mathrm{AICc}$ & $\begin{array}{l}\triangle \mathrm{AICc} \\
\text { Weight }\end{array}$ & $\mathrm{AICc}$ & $\triangle \mathrm{AICc}$ & $\begin{array}{l}\triangle \mathrm{AICc} \\
\text { Weight }\end{array}$ \\
\hline Common Ricker $a$ & 2011.78 & 0 & 0.96 & 1970.60 & 0 & $>0.99$ \\
\hline Stock-specific Ricker $a$, common $\mu_{t}$ & 2018.13 & 6.35 & 0.04 & 1984.57 & 13.97 & $<0.01$ \\
\hline Common Ricker $a$, common $\mu_{t}$ & 2028.79 & 17.01 & $<0.01$ & 1985.76 & 15.16 & $<0.01$ \\
\hline Stock-specific Ricker $a$ & 2031.50 & 19.72 & $<0.01$ & 1995.81 & 25.21 & $<0.01$ \\
\hline Common Ricker $a$, REGION*WTT & 2201.90 & 190.12 & $<0.01$ & 2162.65 & 192.05 & $<0.01$ \\
\hline Stock-specific Ricker $a$, REGION*WTT & 2222.94 & 211.16 & $<0.01$ & 2187.12 & 216.52 & $<0.01$ \\
\hline Common Ricker $a$, common WTT & 2252.84 & 241.06 & $<0.01$ & 2208.92 & 238.32 & $<0.01$ \\
\hline Stock-specific Ricker $a$, common WTT & 2257.81 & 246.03 & $<0.01$ & 2213.34 & 242.74 & $<0.01$ \\
\hline
\end{tabular}


Table 4. Name, region, and point estimates (estimated standard errors) for $d_{i}$, Ricker $a$, Ricker $b_{i}$, and covariance of Ricker $a$ and $b_{i}$, as generated from the stock-recruitment model containing a common Ricker $a$, for 25 index stocks of spring/summer chinook salmon in the Columbia River Basin. Note that $\hat{d}_{i}=\hat{a}-\ln \left(\hat{b}_{i}\right)$, where $e^{\hat{d}_{i}-1}$ is the estimator of maximum recruitment for the $i$ th stock.

\begin{tabular}{|c|c|c|c|c|c|}
\hline Stock Name & Region & $\hat{d}_{i}\left(\hat{\mathrm{SE}}_{i}\right)$ & $\hat{a}(\hat{\mathrm{SE}})$ & $\hat{b}_{i}\left(\hat{\mathrm{SE}}_{i}\right)^{1}$ & $\operatorname{Cov}\left(\hat{a}, \hat{b}_{i}\right)^{1}$ \\
\hline Bear Valley/Elk Creek & $\mathrm{SN}$ & $8.97(0.43)$ & $1.74(0.39)$ & $0.74(0.13)$ & -0.001 \\
\hline Big Sheep/Lick Creek & $\mathrm{SN}$ & $7.31(0.42)$ & $1.74(0.39)$ & $3.88(0.58)$ & -0.003 \\
\hline Catherine Creek & SN & $8.53(0.42)$ & $1.74(0.39)$ & $1.14(0.18)$ & -0.001 \\
\hline Entiat River & $\mathrm{MC}$ & $7.98(0.47)$ & $1.74(0.39)$ & $1.99(0.41)$ & -0.025 \\
\hline Grande Ronde River & $\mathrm{SN}$ & $8.20(0.43)$ & $1.74(0.39)$ & $1.60(0.30)$ & -0.002 \\
\hline Imnaha River & SN & $8.87(0.41)$ & $1.74(0.39)$ & $0.81(0.10)$ & -0.001 \\
\hline John Day Main Stem & $\mathrm{LC}$ & $7.56(0.38)$ & $1.74(0.39)$ & $3.02(0.53)$ & 0.053 \\
\hline John Day Middle Fork & $\mathrm{LC}$ & $8.07(0.39)$ & $1.74(0.39)$ & $1.81(0.33)$ & 0.026 \\
\hline John Day North Fork/Granite & $\mathrm{LC}$ & $9.17(0.38)$ & $1.74(0.39)$ & $0.60(0.10)$ & 0.010 \\
\hline Johnson Creek & SN & $7.76(0.42)$ & $1.74(0.39)$ & $2.47(0.36)$ & -0.002 \\
\hline Klickitat River & $\mathrm{LC}$ & $7.64(0.38)$ & $1.74(0.39)$ & $2.82(0.63)$ & 0.079 \\
\hline Lemhi River & $\mathrm{SN}$ & $9.02(0.43)$ & $1.74(0.39)$ & $0.70(0.12)$ & -0.0005 \\
\hline Lookingglass Creek & $\mathrm{SN}$ & $7.71(0.42)$ & $1.74(0.39)$ & $2.59(0.43)$ & -0.002 \\
\hline Lostine River & $\mathrm{SN}$ & $7.80(0.44)$ & $1.74(0.39)$ & $2.83(0.47)$ & -0.003 \\
\hline Marsh Creek & $\mathrm{SN}$ & $8.32(0.43)$ & $1.74(0.39)$ & $1.42(0.26)$ & -0.001 \\
\hline Methow River & $\mathrm{MC}$ & $9.66(0.52)$ & $1.74(0.39)$ & $0.38(0.11)$ & -0.007 \\
\hline Minam River & $\mathrm{SN}$ & $8.43(0.42)$ & $1.74(0.39)$ & $1.26(0.20)$ & -0.001 \\
\hline Poverty Flat & $\mathrm{SN}$ & $8.81(0.42)$ & $1.74(0.39)$ & $0.86(0.13)$ & -0.0005 \\
\hline Secesh River/Lake Creek & SN & $7.52(0.42)$ & $1.74(0.39)$ & $3.14(0.48)$ & -0.002 \\
\hline Sulphur Creek & $\mathrm{SN}$ & $8.00(0.43)$ & $1.74(0.39)$ & $1.96(0.36)$ & -0.002 \\
\hline Upper Big Creek & $\mathrm{SN}$ & $7.39(0.42)$ & $1.74(0.39)$ & $3.58(0.61)$ & -0.002 \\
\hline Upper Valley Creek & SN & $7.51(0.43)$ & $1.74(0.39)$ & $3.19(0.58)$ & -0.003 \\
\hline Warm Springs River & $\mathrm{LC}$ & $9.98(0.74)$ & $1.74(0.39)$ & $0.33(0.25)$ & 0.028 \\
\hline Wenaha River & SN & $8.84(0.44)$ & $1.74(0.39)$ & $0.84(0.18)$ & -0.001 \\
\hline Wenatchee River & MC & $9.72(0.45)$ & $1.74(0.39)$ & $0.35(0.06)$ & -0.003 \\
\hline
\end{tabular}

${ }^{1}$ Estimates should be divided by 1000 to adjust for rescaling of $\hat{b}_{i}$. 
Table 5. Predictor variables, AICc values, $\triangle \mathrm{AICc}$ values, $\triangle \mathrm{AICc}$ weights, and proportions of largest weight for the set of candidate models attempting to link maximum recruitment of spring/summer chinook salmon with landscape variables. AICc-related values were averaged over 1000 models from 1000 randomly-generated response variables (i.e., $\hat{d}_{i}$ ). $\triangle \mathrm{AICc}$ weights represent degree of plausibility of each model given the data. Proportion of a given model $\triangle \mathrm{AICc}$ weight to the largest one was used as a guideline for selecting which predictor variables (Table 1) to include in the composite model (Table 6).

\begin{tabular}{lcccc}
\hline Predictor Variables & AICc & $\triangle \mathrm{AICc}$ & $\begin{array}{c}\triangle \mathrm{AICc} \\
\text { Weight }\left(w_{i}\right)\end{array}$ & $\begin{array}{c}\text { Proportion } \\
\text { of Largest } w_{i}\end{array}$ \\
\hline WELEV, MNG_FOR, MNG_FW & 65.27 & 0 & 0.37 & 1.00 \\
WELEV, WGEODENS, MNG_FOR, MNG_FW & 67.51 & 2.24 & 0.12 & 0.32 \\
WPRECIP, WELEV, MNG_FOR, MNG_FW & 67.54 & 2.27 & 0.12 & 0.32 \\
MNG_FOR, MNG_FW & 68.00 & 2.73 & 0.09 & 0.24 \\
WMTEMP, WELEV, WGEODENS & 68.53 & 3.26 & 0.07 & 0.19 \\
WPPRECIP, WELEV & 69.27 & 4.00 & 0.05 & 0.14 \\
WPPRECIP, WMTEMP & 69.96 & 4.69 & 0.03 & 0.08 \\
REGION & 69.97 & 4.70 & 0.03 & 0.08 \\
WGEODENS & 70.22 & 4.95 & 0.03 & 0.08 \\
WPPRECIP, WERO, MNG_FOR & 70.40 & 5.13 & 0.03 & 0.08 \\
WPPRECIP, WERO & 71.21 & 5.94 & 0.02 & 0.05 \\
REGION, WGEODENS & 71.41 & 6.14 & 0.02 & 0.05 \\
WPPRECIP, WMTEMP WELEV, WERO & 73.34 & 8.07 & $<0.01$ & $<0.01$ \\
$\begin{array}{l}\text { WPPRECIP, WERO, WGEODENS } \\
\text { WERO, WGEODENS, MNG_FOR, MNG_FW }\end{array}$ & 73.52 & 8.25 & $<0.01$ & $<0.01$ \\
WPPRECIP, WERO, WGEODENS, MNG_FOR & 73.64 & 8.37 & $<0.01$ & $<0.01$
\end{tabular}


Table 6. Model-averaged estimate of standardized regression coefficient and standard error, and lower and upper limits of various confidence intervals for parameters contained in one or more candidate models (Table 5) with $\triangle \mathrm{AICc}$ weights within more than $10 \%$ of the largest $\triangle \mathrm{AICc}$ weight. Confidence intervals not containing 0 are statistically significant at the associated level of confidence.

\begin{tabular}{|c|c|c|c|c|c|c|c|c|}
\hline \multirow[b]{2}{*}{$\begin{array}{l}\text { Model } \\
\text { Parameter }\end{array}$} & \multirow{2}{*}{$\begin{array}{c}\text { Stdzed. } \\
\text { Regr. } \\
\text { Coeff. }\end{array}$} & \multirow[b]{2}{*}{$\begin{array}{l}\text { Std. } \\
\text { Error }\end{array}$} & \multicolumn{2}{|c|}{$90 \% \mathrm{CI}$} & \multicolumn{2}{|c|}{$95 \% \mathrm{CI}$} & \multicolumn{2}{|c|}{$99 \% \mathrm{CI}$} \\
\hline & & & $\begin{array}{c}\text { Lower } \\
\text { Limit }\end{array}$ & $\begin{array}{l}\text { Upper } \\
\text { Limit }\end{array}$ & $\begin{array}{c}\text { Lower } \\
\text { Limit }\end{array}$ & $\begin{array}{l}\text { Upper } \\
\text { Limit }\end{array}$ & $\begin{array}{l}\text { Lower } \\
\text { Limit }\end{array}$ & $\begin{array}{l}\text { Upper } \\
\text { Limit }\end{array}$ \\
\hline INTERCEPT & 8.34 & 0.16 & 8.07 & 8.61 & 8.01 & 8.67 & 7.89 & 8.79 \\
\hline WPPRECIP & -0.17 & 0.18 & -0.48 & 0.14 & -0.54 & 0.20 & -0.67 & 0.33 \\
\hline WMTEMP & 0.13 & 0.31 & -0.40 & 0.66 & -0.51 & 0.77 & -0.74 & 1.00 \\
\hline WELEV & -0.38 & 0.19 & -0.71 & -0.05 & -0.77 & 0.01 & -0.91 & 0.15 \\
\hline WGEODENS & -0.25 & 0.23 & -0.64 & 0.14 & -0.72 & 0.22 & -0.89 & 0.39 \\
\hline MNG_FOR & -0.51 & 0.22 & -0.89 & -0.13 & -0.96 & -0.06 & -1.13 & 0.11 \\
\hline MNG_FW & -0.24 & 0.22 & -0.62 & 0.14 & -0.69 & 0.21 & -0.86 & 0.38 \\
\hline
\end{tabular}

